\title{
Patient education in rheumatoid arthritis: is the needs-based approach the way forward?
}

\author{
Mwidimi Ndosi $^{1} \cdot$ Ade Adebajo $^{2}$ \\ Received: 11 August 2015 /Revised: 15 August 2015 / Accepted: 18 August 2015 /Published online: 18 September 2015 \\ (C) International League of Associations for Rheumatology (ILAR) 2015
}

In recent years, the assessment of patients' needs has become an important area of research for several reasons; expenditure on healthcare has risen faster than the cost increases reported in other sectors of the economy, and medical advances and demographic changes will continue the upward pressure on costs. At the same time, the resources available for healthcare are limited, and the rising expectations of the public have led to greater concerns about the quality of the services they receive. The idea that finance and resources should be directed towards addressing the priority needs of patients is easy to agree with. However, identifying and quantifying these 'needs' is a more difficult task, yet essential, especially for people living with chronic diseases such as rheumatoid arthritis (RA).

Patient education for people living with chronic diseases such as RA is extremely important as this enables them to adapt and cope with the effects of the disease and treatments. While research has identified a whole range of benefits such as improved disease knowledge, self-efficacy, concordance with treatment and physical and psychological health status [1], it is important to emphasise that patient education is heterogeneous in terms of content, methods of delivery and whether it is group or individual based. Further clinical heterogeneity is contributed to by the characteristics of patients and the timing of the education; whether it is given in early/late disease or at different points along their disease trajectory. This poses methodological challenges when assessing and

Ade Adebajo

a.o.adebajo@sheffield.ac.uk

1 School of Healthcare, University of Leeds, Leeds, UK

2 Faculty of Medicine, Dentistry and Health, University of Sheffield, Sheffield, UK reporting the 'collective effects' of patient education [2]; consequently, generalisation of 'effects' in this area is nearly impossible. Since RA affects patients differently and patients are likely to have different educational needs and priorities, benefits of education are likely to be far-ranging. For example, some patients in early disease may want education to help them understand the disease process and the effects of medication, and the goal of education may be to help increase their knowledge and confidence; other patients at a different stage may need a self-management approach which focuses on their current needs to help increase knowledge and change attitudes, beliefs and behaviour.

Education needs assessment is important not least because patients have different needs, but also because health providers and patients have differing views of what kind of patient education should be given [3]. Needs assessment fits very well with the principle of shared decision-making which is regarded as the pinnacle of patient-centred care and should guide the modern healthcare consultation. In this approach to care, the patient brings his/her experience of living with RA, preferences, needs and values into the consultation, and these are combined with the clinician's skills and knowledge based on the best scientific evidence and provides the care that is respectful of and responsive to patient's needs [4, 5]. In the context of education, this is consistent with the principles of adult learning theory, which recognises that individuals are different, having different learning needs, which are likely to be different at different time points [6]. One of the European League Against Rheumatism recommendations for patient education [1] specifies 'All people with inflammatory arthritis should have access to and be offered patient education throughout the course of their disease including as a minimum; at diagnosis, at pharmacological treatment change and when required by the patient's physical or psychological condition'. The systematic review underlying the 
recommendations found level 1 evidence for the effectiveness of patient-centred education. Therefore, the recommendations further specify that the content and delivery of patient education should be individually tailored and needs-based [1].

Assessing the perceived educational needs can follow the health needs assessment model [6]. Health needs assessment is a systematic method for reviewing the health issues facing a population, leading to agreed priorities and resource allocation that will improve health and reduce inequalities [7]. Although the concept of health needs assessment and the systematic method of performing the assessment is commendable, the focus is invariably on the population group rather than the individual patient. What is needed for the assessment of educational needs is a systematic approach, but one which engages the patient and encourages shared decision-making [4]. The use of assessment tools such as the educational needs assessment tool (ENAT) UK [8] may help to systematically assess individual patient's educational needs, focusing on the 'micro' rather than the 'macro'. The ENAT has been validated and shown to have a unidimensional scale in RA and in other rheumatic diseases [9-12]. This validates the underlying latent construct (the educational needs) and enables quantification as well as an accurate estimation of the education needs of people with rheumatic diseases. This has been shown to be useful both in research [13-18] and in clinical settings [19]. The ENAT has been shown to help enable patients to effectively identify their educational needs and think of questions which they would not have otherwise considered, before their consultation with the clinician [19]. While tools such as the ENAT help to assess patients' perceived education needs, sometimes patient's condition may bring up other needs (from the health professionals' point of view) such as treatment changes and prevention of comorbidities, all of which may need to be addressed during the consultation. Addressing the patients' needs before any other educational objectives may help to ensure that the patient is engaged in the clinical decisionmaking and disease management. For the clinician, the ENAT helps to objectively identify the perceived learning needs of the patient and ensure that these are prioritised alongside or before any other clinician-perspectives, and also that they are incorporated in the educational goal-setting. This needsbased approach is likely to enhance patients' engagement, shared decision-making and improve their selfmanagement skills. This is validated by a recent randomised controlled trial which has shown that needs-based patient education in RA helps to improve self-efficacy and some aspects of health status [18].

With respect to patient education, the last five decades have seen an evolution of the patient/clinician relationship dynamics [20], where the clinicians have moved from the position of power as the sole knowledge owners and transmitters, and patients from an inferior position of passive recipients to a more progressive dynamic of shared decision-making. The current standard is patient-centred care which is responsive to individual patient preferences, needs, and values. In the same vein, it is hoped that needs-based approach in patient education will be the way forward.

Disclosures None.

\section{References}

1. Zangi HA, Ndosi M, Adams J, Andersen L, Bode C, Boström C, van Eijk-Hustings Y, Gossec L, Korandová J, Mendes G, Niedermann K, Primdahl J, Stoffer M, Voshaar M, van Tubergen A (2015) EULAR recommendations for patient education for people with inflammatory arthritis. Ann Rheum Dis 74(6):954-962

2. Gagnier JJ, Moher D, Boon H, Beyene J, Bombardier C (2012) Investigating clinical heterogeneity in systematic reviews: a methodologic review of guidance in the literature. BMC Med Res Methodol 12(1):111

3. Bishop P, Kirwan J, Windsor K (1997) The ARC patient literature evaluation project: brief report: arthritis and rheumatism council for research

4. Institute of Medicine (2001) Crossing the quality chasm : a new health system for the 21 st century. National Academy Press, Washington

5. Chewning B, Bylund CL, Shah B, Arora NK, Gueguen JA, Makoul G (2012) Patient preferences for shared decisions: a systematic review. Patient Educ Couns 86(1):9-18

6. Bryan RL, Kreuter MW, Brownson RC (2009) Integrating adult learning principles into training for public health practice. Health Promot 10(4):557-563

7. Hooper J, Longworth P (2002) Health needs assessment workbook: health development agency

8. Hardware B, Anne Lacey E, Shewan J (2004) Towards the development of a tool to assess educational needs in patients with arthritis. Clin Eff Nurs 8(2):111-117

9. Ndosi M, Bremander A, Hamnes B, Horton M, Kukkurainen ML, Machado P, Marques A, Meesters J, Stamm TA, Tennant A, de la Torre-Aboki J, Vliet Vlieland TP, Zangi HA, Hill J (2014) Validation of the educational needs assessment tool as a generic instrument for rheumatic diseases in seven European countries. Ann Rheum Dis 73(12):2122-2129

10. Sierakowska M, Sierakowski S, Sierakowska J, Horton M, Ndosi M (2014) Developing the Polish Educational Needs Assessment Tool (Pol-ENAT) in rheumatoid arthritis and systemic sclerosis: a cross-cultural validation study using Rasch analysis. Qual Life Res 24(3):721-733

11. Ndosi M, Hill J, Tennant A, Hale C, Adebajo A (2009) Validation of the educational needs assessment tool in 6 rheumatic diseases. Rheumatology (Oxford) 48:I23-I24

12. Ndosi M, Tennant A, Bergsten U, Kukkurainen ML, Machado P, de la Torre-Aboki J, Vlieland TPMV, Zangi HA, Hill J (2011) Crosscultural validation of the Educational Needs Assessment Tool in RA in 7 European countries. BMC Musculoskelet Disord 12:110

13. Gronning K, Skomsvoll JF, Rannestad T, Steinsbekk A (2012) The effect of an educational programme consisting of group and individual arthritis education for patients with polyarthritis-a randomised controlled trial. Patient Educ Couns 88(1):113-120

14. Gronning K, Rannestad T, Skomsvoll JF, Rygg LO, Steinsbekk A (2014) Long-term effects of a nurse-led group and individual patient education programme for patients with chronic inflammatory polyarthritis - a randomised controlled trial. J Clin Nurs 23(7-8): 1005-1017 
15. Zirkzee EJ, Ndosi ME, Vlieland TP, Meesters JJ (2014) Measuring educational needs among patients with systemic lupus erythematosus (SLE) using the Dutch version of the Educational Needs Assessment Tool (D-ENAT). Lupus 23(13):1370-1376

16. Meesters JJ, Vliet Vlieland TP, Hill J, Ndosi ME (2009) Measuring educational needs among patients with rheumatoid arthritis using the Dutch version of the Educational Needs Assessment Tool (DENAT). Clin Rheumatol 28(9):1073-1077

17. Dragoi RG, Ndosi M, Sadlonova M, Hill J, Duer M, Graninger W, Smolen J, Stamm TA (2013) Patient education, disease activity and physical function: can we be more targeted? A cross sectional study among people with rheumatoid arthritis, psoriatic arthritis and hand osteoarthritis. Arthritis Res Ther 15(5):R156
18. Ndosi M, Johnson D, Young T, Hardware B, Hill J, Hale C, Maxwell J, Roussou E, Adebajo A (2015) Effects of needs-based patient education on self-efficacy and health outcomes in people with rheumatoid arthritis: a multicentre, single blind, randomised controlled trial. Ann Rheum Dis. doi:10.1136/annrheumdis-2014207171

19. Hardware B, Johnson D, Hale C, Ndosi M, Adebajo A (2015) Patients and nursing staff views of using the education needs assessment tool in rheumatology clinics: a qualitative study. J Clin Nurs 24(7-8):1048-1058

20. Hoving C, Visser A, Mullen PD, van den Borne B (2010) A history of patient education by health professionals in Europe and North America: from authority to shared decision making education. Patient Educ Couns 78(3):275-281 